\title{
Inhaled iloprost for the treatment of
}

\section{pulmonary hypertension}

\author{
H. Olschewski
}

\begin{abstract}
Prostacyclin and its analogues (prostanoids) are potent vasodilators, and exhibit antithrombotic, antiproliferative and anti-inflammatory properties. Pulmonary arterial hypertension (PAH) is characterised by vasoconstriction, thrombosis and proliferation, and is associated with reduced synthesis of endogenous prostacyclin. This provides a strong rationale for the use of prostanoids to treat PAH, a concept that is now supported by more than two decades of clinical research and experience. Intravenous and subcutaneous prostanoids have clearly demonstrated efficacy in severe PAH, but adverse events related to the drug delivery system, systemic side-effects and tachyphylaxis have driven research into alternative prostanoid treatments.

Iloprost is administered by inhalation, and thus avoids most of the systemic side-effects associated with i.v. or subcutaneous prostanoid infusion. Two randomised controlled 12-week trials in patients with PAH have demonstrated efficacy and a favourable safety profile for iloprost as monotherapy (the AIR trial) and in combination with oral bosentan (STEP). Open-label uncontrolled long-term studies of inhaled iloprost therapy indicate that this treatment may improve long-term outcomes in PAH.
\end{abstract}

KEYWORDS: Clinical trials, iloprost, inhalation, pulmonary hypertension, review

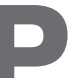

rostacyclin has potent vasodilatory, antithrombotic, anti-inflammatory and antiproliferative effects [1]. Studies of excreted prostacyclin metabolite levels and prostacyclin synthase expression in lung tissue indicate that prostacyclin synthesis is reduced in patients with pulmonary hypertension (PH) compared with healthy controls $[2,3]$, providing a rationale for treating $\mathrm{PH}$ with prostacyclin analogues (prostanoids).

The earliest therapy in this class to be approved for the treatment of pulmonary arterial hypertension (PAH; group 1 according to the Venice $\mathrm{PH}$ classification [4]) was the intravenous prostanoid epoprostenol, which improved exercise capacity, quality of life, cardiopulmonary haemodynamics and survival compared with conventional therapy in a 12-week, randomised, open study of 81 patients with primary $\mathrm{PH}$ (now classified as idiopathic and familial PAH) [5].

Although efficacious, epoprostenol is unstable at room temperature, and the requirement for i.v. administration renders the therapy prone to serious complications, including catheter-related infections and thrombosis. It is also possible that epoprostenol may not be able to halt disease progression in cases of aggressive $\mathrm{PAH} ;$ i.v. epoprostenol showed a clear survival benefit compared with historical control data in a retrospective study, but survival rates remained relatively poor, with only $70 \%$ of patients remaining alive on epoprostenol therapy after $2 \mathrm{yrs}$ of treatment [6]. Additional limitations of epoprostenol include systemic side-effects, such as pain, diarrhoea and systemic hypotension, ventilation/ perfusion mismatch and tachyphylaxis [7].

Since the introduction of epoprostenol, prostanoids with improved stability and simpler modes of administration have been developed and investigated in double-blind, randomised, controlled studies [8]. Subcutaneous treprostinil improved exercise capacity, cardiopulmonary haemodynamics, dyspnoea, and signs and symptoms of $\mathrm{PH}$, compared with placebo in 470 patients with PAH [9], whereas oral beraprost improved exercise capacity and dyspnoea relative to placebo but did not improve functional class or cardiopulmonary haemodynamics in 130 patients with PAH [10].

Iloprost is a stable analogue of prostacyclin that can be administered by inhalation, avoiding the systemic side-effects associated with i.v. administration. Administration of iloprost by inhalation also causes selective vasodilation of well-ventilated regions of the lung (intrapulmonary selectivity), ensuring optimal gas exchange. The benefits of
CORRESPONDENCE

H. Olschewski

Pulmonology Division

Dept of Internal Medicine

Medical University of Graz

Auenbruggerplatz 20

8036 Graz

Austria

Fax: 433163852183

E-mail: horst.olschewski@medunigraz.at

Received:

December 082008

Accepted after revision:

December 172008

STATEMENT OF INTEREST

H. Olschewski has received reimbursement for attending a symposium, and fees for speaking and consulting from Bayer Schering AG, Actelion, Encysive, GSK, Pfizer and Unither; has received funds for research and organising education from Actelion, Bayer Schering AG and Encysive; and has received fees for consulting from Bayer Schering AG, CoTherix, GSK and Myogen.

\section{PROVENANCE}

Publication of this peer-reviewed article was made possible by funding from Bayer Schering Pharma AG, Germany (principal Sponsor, European Respiratory Review issue 111). 
inhaled iloprost were first demonstrated in mechanically ventilated patients with acute respiratory distress syndrome. Aerosolised iloprost had similar pulmonary and intrapulmonary selectivity to inhaled nitric oxide, significantly reducing pulmonary arterial pressure $(P \mathrm{pa})$ but not systemic arterial pressure, redistributing blood flow to ventilated areas of the lungs, and improving oxygenation $[11,12]$.

\section{UNCONTROLLED STUDIES OF ILOPROST IN PATIENTS WITH PH}

Following the initial proof-of-concept study, the properties of aerosolised iloprost were investigated in patients with $\mathrm{PH}$. Aerosolised iloprost and i.v. prostacyclin both significantly reduced pulmonary vascular resistance (PVR) in a study of six patients with severe $\mathrm{PH}$, but only iloprost showed pulmonary selectivity and improved arterial oxygen saturation $\left(\mathrm{Sa}_{\mathrm{a}} \mathrm{O}_{2}\right)$. Aerosolised iloprost had a similar efficacy profile to aerosolised prostacyclin, but its pulmonary vasodilatory effects were more durable, lasting 60-120 min compared with 10$30 \mathrm{~min}$ for prostacyclin [13].

The promising results of this first study in patients with $\mathrm{PH}$ led the investigators to initiate long-term treatment of one patient, who had severe PAH associated with limited systemic sclerosis, or CREST syndrome (severe pulmonary hypertension associated with calcinosis, Raynaud's phenomenon, oesophageal dysfunction, sclerodactyly and telangiectasia), with aerosolised iloprost. Inhalation of iloprost caused a dramatic reduction in $\mathrm{Ppa}$, accompanied by increases in cardiac output and $\mathrm{Sa}_{1} \mathrm{O}_{2}$. The patient demonstrated sustained haemodynamic and clinical improvement over the course of 2 yrs of treatment, with no indication of tachyphylaxis (fig. 1) [13].

The German PPH (Primary Pulmonary Hypertension) Study Group investigated the effects of iloprost in 19 patients who had $\mathrm{PH}$ with progressive right heart failure despite receiving maximum conventional therapy [14]. The patients received 50$200 \mu \mathrm{g}$ aerosolised iloprost per day, in six to 12 daily doses, over a period of 3 months. A high mortality rate was observed among this population of severely ill patients (21\%), but New York Heart Association (NYHA) functional class improved from IV to III in eight (42\%) patients and 6-min walk distance (6MWD; a standard measure of exercise capacity) increased by $148 \mathrm{~m}(\mathrm{p}=0.048)$ from baseline, indicating recompensation of the right ventricle. Pre-inhalation (trough) haemodynamics showed significant improvement from baseline after 3 months of treatment.

A smaller study investigated the effects of inhaled iloprost in four patients with severe $\mathrm{PH}$ over a 7-month period, and reported progressive long-term improvements in $P$ pa and exercise capacity [15]. Sustained effects on exercise capacity and pulmonary haemodynamics have also been demonstrated in a study of 24 patients with primary $\mathrm{PH}$. Iloprost at a daily dose of $100-150 \mu \mathrm{g}$ improved mean $6 \mathrm{MWD}$ by $80 \mathrm{~m}$ from baseline after 1 yr $(\mathrm{p}<0.001)$. Mean Ppa and PVR decreased, and cardiac output increased significantly [16].

A case study of a female with circulatory shock and decompensated right heart failure due to primary $\mathrm{PH}$ suggested that inhaled iloprost may be beneficial in extreme cases of $\mathrm{PH}$. The patient did not tolerate i.v. prostacyclin therapy; however, inhaled iloprost was tolerated well, and this treatment dramatically improved haemodynamics, gas exchange and clinical status from baseline [17].

No PAH therapy has yet been approved for the treatment of $\mathrm{PH}$ associated with lung disease (Venice $\mathrm{PH}$ classification group 3 [4]). In a study of eight patients with $\mathrm{PH}$ associated with lung fibrosis, i.v. prostacyclin decreased $P$ pa but worsened ventilation/perfusion matching. In a subsequent test, inhaled prostacyclin (iloprost) circumvented the problem of ventilation/ perfusion mismatching, and reduced $P$ pa without affecting systemic arterial pressure [18]. Inhaled iloprost also improved ventilation/perfusion matching from baseline in six patients with chronic obstructive pulmonary disease [19]. Although these results suggest that iloprost may benefit patients with $\mathrm{PH}$ associated with lung disease, it should be noted that a recent randomised, placebo-controlled trial of iloprost in patients with $\mathrm{PH}$ and pulmonary fibrosis (the ACTIVE study: A Clinical Trial in IPF to Improve Ventilation and Exercise) found a worsening in 6MWD with treatment [20].

\section{KEY CLINICAL STUDIES OF INHALED ILOPROST Inhaled iloprost as monotherapy}

The AIR study

The AIR (Aerosolised Iloprost Randomised) study was a double-blind, randomised, controlled trial of inhaled iloprost therapy in 203 patients with selected forms of severe PAH and chronic thromboembolic PH in NYHA functional class III or IV [21]. The study lasted 12 weeks, and its primary end-point was an increase in 6MWD of $\geqslant 10 \%$ and improvement in NYHA class, in the absence of clinical deterioration or death. Clinical deterioration was defined as two or more of the following: refractory systolic arterial hypotension; worsening right ventricular failure; rapidly progressing cardiogenic, hepatic or renal failure; a decrease of $\geqslant 30 \%$ in $6 \mathrm{MWD}$; and decline in measures of haemodynamic function. This rigorous primary end-point was met by $16.8 \%$ of iloprost-treated patients compared with $4.9 \%$ of those receiving placebo $(\mathrm{p}=0.007)$.

A substantial number of patients met less strict criteria for clinical improvement. Nearly $40 \%$ of the iloprost group increased their $6 \mathrm{MWD}$ by $\geqslant 10 \%$, and $24.8 \%$ improved by at least one NYHA functional class. The mean placebo-adjusted increase in 6MWD was $36.4 \mathrm{~m}$ in the iloprost group $(\mathrm{p}=0.004$; fig. 2). Cardiopulmonary haemodynamics deteriorated in the placebo group, whereas pre-inhalation values in the iloprost group at the end of the study period were similar to baseline values, and improved following inhalation of the drug. The mean Mahler dyspnoea score was significantly increased in the iloprost group compared with the placebo group. Healthrelated quality of life (measured using the EuroQol visualanalogue scale) improved significantly from baseline in the iloprost group, and remained virtually unchanged in the placebo group. Fewer patients died or deteriorated in the iloprost group $(4.9 \%)$ compared with the placebo group $(11.8 \%)$, but this difference was not statistically significant $(\mathrm{p}=0.09)$.

Reported side-effects were mild and generally typical for prostanoid therapy (flushing and jaw pain). There was a slight increase in the number of patients reporting coughing in the iloprost group compared with the placebo group. Syncopal 

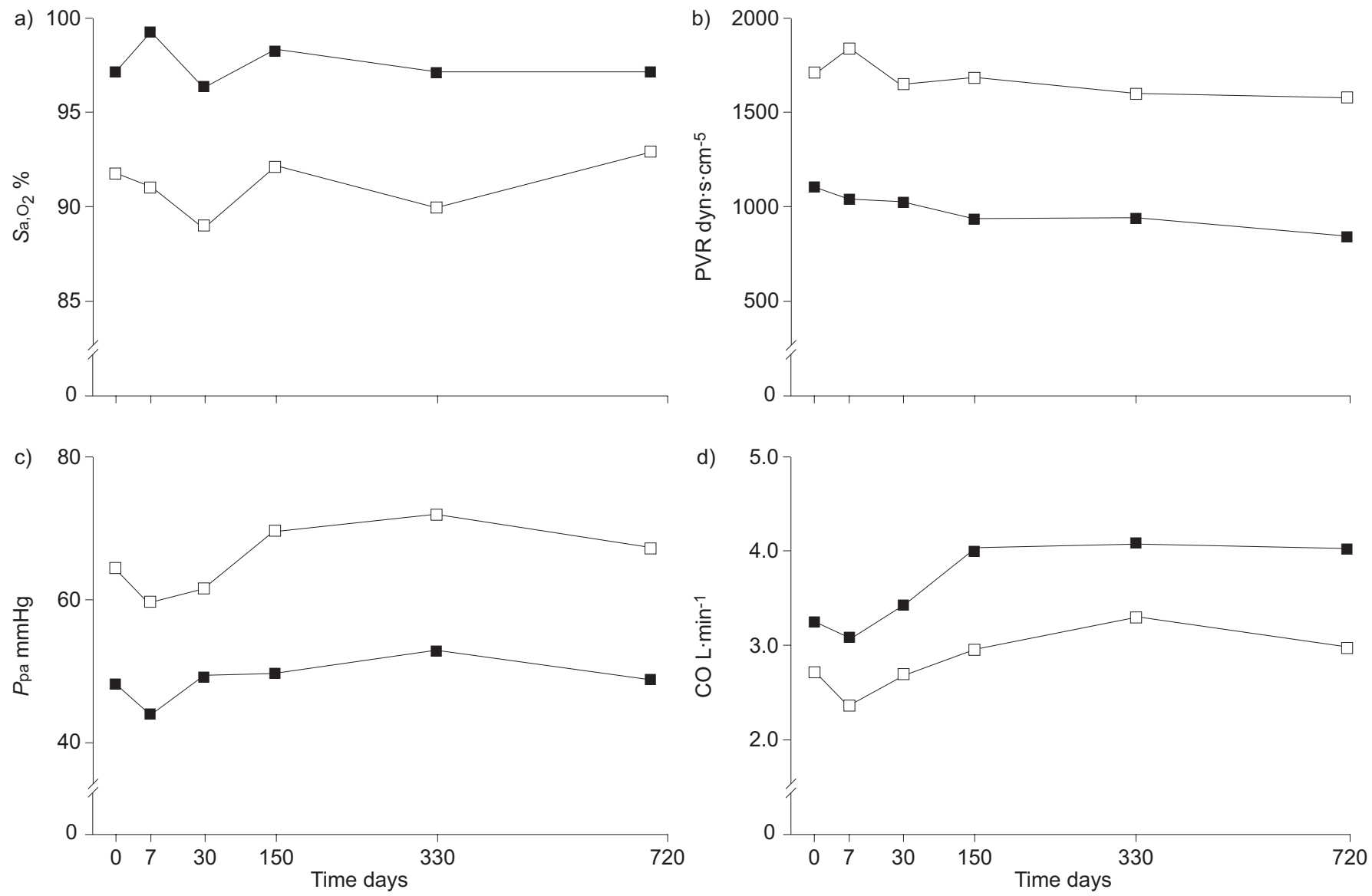

FIGURE 1. Maintenance of response to iloprost inhalation during long-term therapy. A female patient with CREST syndrome was treated with inhaled iloprost (100 $\mu \mathrm{g} \cdot$ day $^{-1}$ in six daily doses) and monitored for 2 yrs. Measurements taken before ( $\square$ ) and immediately after ( $\square$ ) inhalation of iloprost are shown. CREST: severe pulmonary hypertension associated with calcinosis, Raynaud's phenomenon, oesophageal dysfunction, sclerodactyly and telangiectasia; $\mathrm{Sa}, \mathrm{O}_{2}$ : arterial oxygen saturation; PVR: pulmonary vascular resistance; Ppa: pulmonary arterial pressure; CO: cardiac output. Modified and reproduced from [13] with permission from the publisher.

events occurred at a similar frequency in both groups, but were more often described as serious adverse events in the iloprost group (five reports of serious syncope, compared with none in the placebo group). The type of $\mathrm{PH}$ had no effect on the outcome in terms of 6MWD, NYHA functional class, Mahler dyspnoea score, clinical deterioration and death.

\section{Inhaled iloprost in combination therapy}

The COMBI study

The COMBI (Combination therapy of Bosentan and aerosolised Iloprost in idiopathic pulmonary arterial hypertension) study investigated the effect of inhaled iloprost as an add-on to endothelin receptor antagonist (bosentan) monotherapy in 40 patients with idiopathic PAH in a 12-week, open, randomised, controlled trial [23]. The primary end-point was the change in $6 \mathrm{MWD}$ at 12 weeks, and secondary end-points included functional class, quality of life (assessed using the EuroQoL questionnaire) and clinical deterioration (defined as the occurrence of death, hospital admission for right heart failure, deterioration in functional class or a decrease in 6MWD by $20 \%$ or to $<150 \mathrm{~m}$ ). The study was terminated early because a preliminary analysis predicted failure with respect to the predetermined sample size. The sample size had been calculated based on a $45 \mathrm{~m}$ difference in 6MWD between the iloprost and placebo groups, which did not turn out to be realistic in combination therapy. No significant differences were observed between the active group and placebo group for any of the end-points, although 6MWD improved in more patients in the iloprost group. A number of factors may have contributed to the failure of this trial: the fact that three patients who experienced marked clinical deterioration were all in the iloprost group; the small sample size at the time of early discontinuation; the open-label design; the severity of disease in the study population (all patients were in functional class III); and the timing of the assessments (1-3 h after the last inhalation of iloprost). Another study of iloprost in combination with bosentan, performed using a blinded and placebocontrolled design, was published in the same year (STEP: Safety and pilot efficacy Trial in combination with bosentan for Evaluation in Pulmonary arterial hypertension; see following section) and found significant improvements in Ppa and PVR directly after inhalation of iloprost, but not before.

The STEP study

The STEP study was a 12-week, double-blind, randomised, controlled trial of iloprost as an add-on to bosentan monotherapy in 67 patients with $\mathrm{PAH}$ (55\% idiopathic PAH) [22]. The study focused on safety as the primary end-point. Efficacy 

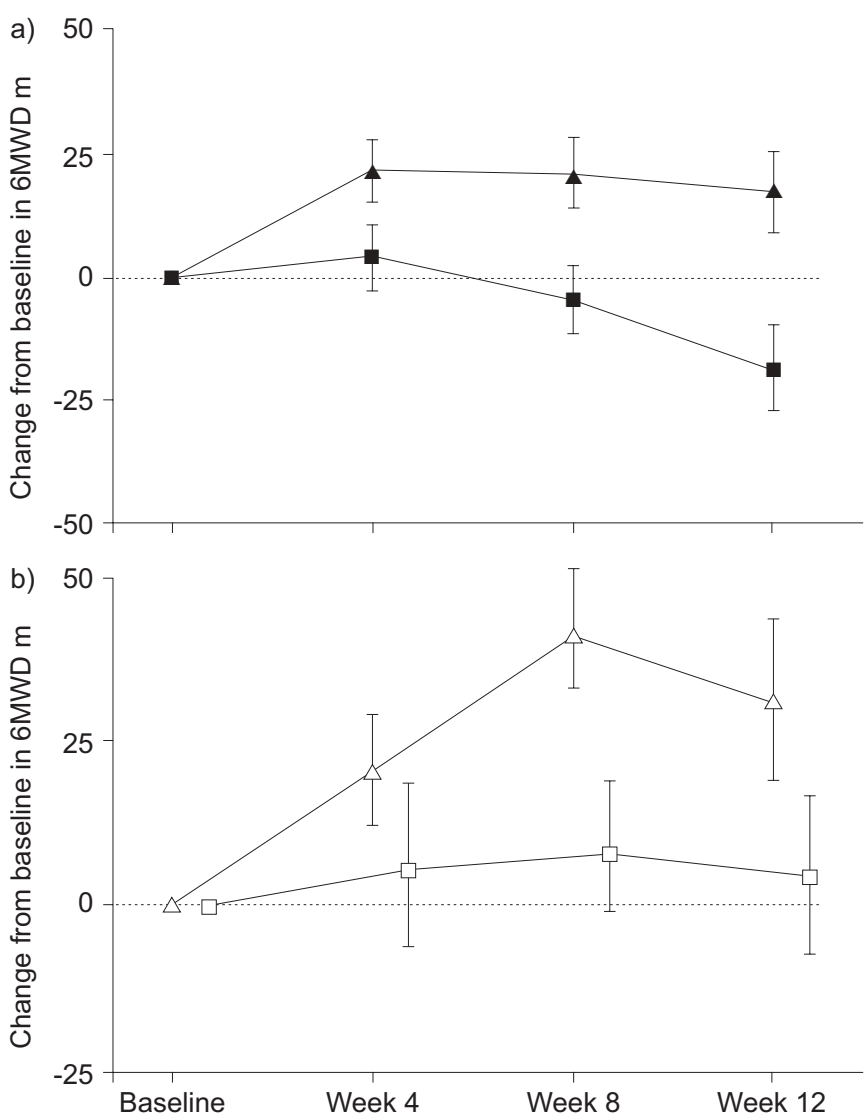

FIGURE 2. Inhaled iloprost effects on 6-min walk distance (6MWD) in patients with pulmonary arterial hypertension in two pivotal phase-3 randomised controlled trials. Patients were treated with: a) iloprost $(\mathbf{\Lambda} ; n=101)$ or placebo $(\mathbf{\square} ; n=102)$ on top of conventional therapy in the AIR trial ( $p=0.004$ at week 12); or b) iloprost $(\triangle ; n=32)$ or placebo $(\square ; n=33)$ on top of conventional therapy and bosentan in the STEP study $(p=0.051$ at week 12). Modified from [21, 22] with permission from the publishers

end-points included change from baseline in 6MWD, and alteration of NYHA functional class, haemodynamic parameters and time to clinical deterioration, prospectively defined as PAH-related death, hospitalisation or early study discontinuation owing to worsening $\mathrm{PAH}$, initiation of new $\mathrm{PAH}-$ specific therapy, lung transplantation or atrial septostomy.

STEP results indicated that addition of iloprost to bosentan had a favourable safety profile. Adverse events were again typical for the prostanoid class and the delivery system; coughing was frequently reported (40\% of the iloprost group and $19 \%$ of the placebo group), but was mild to moderate in severity and did not result in discontinuation of the treatment. Syncope, which raised concerns in the AIR study, was only reported for one iloprosttreated patient in the STEP study and was classified as nonserious. The results of the STEP study also showed a clear tendency for improved exercise capacity compared with placebo $(\mathrm{p}=0.051$; fig. 2) and significant improvement in NYHA functional class $(p=0.002)$ and time to clinical deterioration $(p=0.022)$.

\section{LONG-TERM STUDIES OF INHALED ILOPROST THERAPY IN PAH \\ Long-term studies of first-line inhaled iloprost}

In a study performed in Germany by OpITz et al. [24], a total of 76 patients with idiopathic PAH were treated with inhaled iloprost $\left(100 \mu \mathrm{g} \cdot\right.$ day $^{-1}$ in six daily doses) for up to $5 \mathrm{yrs}$, and clinical, haemodynamic and exercise parameters were monitored. No serious side-effects causing withdrawal from treatment were reported. Survival in the study population was higher than would have been expected without treatment; $49 \%$ of the study population survived for $5 \mathrm{yrs}$, whereas estimated survival without treatment (according to the National Institutes of Health survival probability formula [25]) was 32\% (table 1). However, event-free survival (defined as freedom from death, transplantation, switch to i.v. therapy or addition of oral therapy) was relatively poor, falling to $13 \%$ after 5 yrs.

The results of the study implied that only a minority of patients could be stabilised in the long term with inhaled iloprost monotherapy [24]. However, the study population consisted of seriously ill patients receiving compassionate treatment, and the results should not be extrapolated to all patients with PAH. In addition, escalation of iloprost dose was not permitted, and the patients' adherence to the treatment regimen was not assessed. Furthermore, the reported eventfree survival rate may not accurately reflect clinical stability. The definition of event-free survival excluded those patients who initiated treatment with oral therapy during the course of the study, and reimbursement issues associated with the unapproved use of iloprost may have introduced a bias towards oral bosentan, which received regulatory approval for the treatment of PAH in Germany during the study period.

Data from a long-term, open-label extension of the AIR study (71 patients) revealed that NYHA functional class improved in $41 \%$ and $76 \%$ of patients treated with inhaled iloprost after 1 and 3 yrs, respectively. The survival rate was $83 \%$ at $1 \mathrm{yr}, 78 \%$ at 2 yrs and $58 \%$ at 5 yrs [26].

TABLE 1 Survival of patients treated with first-line inhaled iloprost compared with estimated survival of untreated patients ${ }^{\#}$ 
An additional prospective, 2-yr, open-label study was initiated independently of the AIR study. A total of 63 patients with primary $\mathrm{PH}$ (idiopathic or familial $\mathrm{PAH}$ ) or secondary $\mathrm{PH}$ were treated with inhaled iloprost for up to 2 yrs, at a daily dose of $\sim 24 \mu \mathrm{g}$ divided into six inhalations per day. Long-term treatment with inhaled iloprost was well tolerated in the study. The overall survival rate at 2 yrs was $85 \%$, and patients with primary PAH $(n=40)$ had a survival rate of $91 \%$ [27]. The latter appeared higher than the predicted 2-yr survival rate without treatment for patients with primary $\mathrm{PAH}$, which was $63 \%$ according to the formula proposed by D'Alonzo et al. [25].

\section{Open-label extension of STEP}

A total of 30 patients from the STEP placebo group and 30 patients from the iloprost group were enrolled into an openlabel, 12-month extension study [28]. Overall survival during the extension study was $97 \%$, with one death in the ex-iloprost group and one death in the ex-placebo group. Neither death was related to iloprost. Iloprost in combination with bosentan was well tolerated over the 1-yr study period, and both patient groups showed similar improvements in 6MWD (ex-iloprost: +30 m; ex-placebo: $+27 \mathrm{~m}$ ) and NYHA functional class $(55 \%$ and $53 \%$ improved by more than one functional class in the exiloprost and ex-placebo groups, respectively). However, clinical worsening occurred in $23 \%$ of ex-iloprost patients versus $43 \%$ of ex-placebo patients. This result suggests that withholding prostanoid therapy for 3 months can adversely affect the clinical outcome.

\section{CONCLUSIONS}

Two double-blind, randomised, controlled trials have demonstrated that inhaled iloprost has a favourable safety profile and is effective in patients with pulmonary arterial hypertension in New York Heart Association functional classes III and IV [21, 23]. Results of a smaller, uncontrolled study suggest that inhaled iloprost may also be beneficial in patients with progressive right heart failure despite maximum conventional treatment [14]. Long-term, open-label studies have not raised any safety concerns, and have given strong indications that treatment with inhaled iloprost may improve survival rates. Furthermore, evidence from the long-term extension of the STEP study [28] suggests that withholding prostanoid therapy can be detrimental to clinical course.

\section{ACKNOWLEDGEMENTS}

The author would like to thank C. Mulligan of Oxford PharmaGenesis who provided medical writing assistance funded by Bayer Schering Pharma AG.

\section{REFERENCES}

1 Gomberg-Maitland M, Olschewski H. Prostacyclin therapies for the treatment of pulmonary arterial hypertension. Eur Respir J 2008; 31: 891-901.

2 Tuder RM, Cool CD, Geraci MW, et al. Prostacyclin synthase expression is decreased in lungs from patients with severe pulmonary hypertension. Am J Respir Crit Care Med 1999; 159: 1925-1932.

3 Christman BW, McPherson CD, Newman JH, et al. An imbalance between the excretion of thromboxane and prostacyclin metabolites in pulmonary hypertension. N Engl J Med 1992; 327: 70-75.

4 Simonneau G, Galie N, Rubin LJ, et al. Clinical classification of pulmonary hypertension. J Am Coll Cardiol 2004; 43: Suppl. 12, 5S-12S.

5 Barst RJ, Rubin LJ, Long WA, et al. A comparison of continuous intravenous epoprostenol (prostacyclin) with conventional therapy for primary pulmonary hypertension. The Primary Pulmonary Hypertension Study Group. N Engl J Med 1996; 334: 296-302.

6 Sitbon O, Humbert M, Nunes H, et al. Long-term intravenous epoprostenol infusion in primary pulmonary hypertension: prognostic factors and survival. J Am Coll Cardiol 2002; 40: 780-788.

7 Gessler T, Seeger W, Schmehl T. Inhaled prostanoids in the therapy of pulmonary hypertension. J Aerosol Med 2008; 21: $1-12$.

8 Humbert M, Sitbon O, Simonneau G. Treatment of pulmonary arterial hypertension. $N$ Engl J Med 2004; 351: 1425-1436.

9 Simonneau G, Barst RJ, Galie N, et al. Continuous subcutaneous infusion of treprostinil, a prostacyclin analogue, in patients with pulmonary arterial hypertension: a double-blind, randomized, placebo-controlled trial. Am J Respir Crit Care Med 2002; 165: 800-804.

10 Galie N, Humbert M, Vachiery JL, et al. Effects of beraprost sodium, an oral prostacyclin analogue, in patients with pulmonary arterial hypertension: a randomized, doubleblind, placebo-controlled trial. J Am Coll Cardiol 2002; 39: 1496-1502.

11 Walmrath D, Schneider T, Pilch J, Grimminger F, Seeger W. Aerosolised prostacyclin in adult respiratory distress syndrome. Lancet 1993; 342: 961-962.

12 Walmrath D, Schneider T, Schermuly R, Olschewski H, Grimminger F, Seeger W. Direct comparison of inhaled nitric oxide and aerosolized prostacyclin in acute respiratory distress syndrome. Am J Respir Crit Care Med 1996; 153: 991-996.

13 Olschewski H, Walmrath D, Schermuly R, Ghofrani A, Grimminger F, Seeger W. Aerosolized prostacyclin and iloprost in severe pulmonary hypertension. Ann Intern Med 1996; 124: 820-824.

14 Olschewski $\mathrm{H}$, Ghofrani HA, Schmehl $\mathrm{T}$, et al. Inhaled iloprost to treat severe pulmonary hypertension. An uncontrolled trial. German PPH Study Group. Ann Intern Med 2000; 132: 435-443.

15 Stricker H, Domenighetti G, Fiori G, Mombelli G. Sustained improvement of performance and haemodynamics with long-term aerosolised prostacyclin therapy in severe pulmonary hypertension. Schweiz Med Wochenschr 1999; 129: 923-927.

16 Hoeper MM, Schwarze M, Ehlerding S, et al. Long-term treatment of primary pulmonary hypertension with aerosolized iloprost, a prostacyclin analogue. $N$ Engl J Med 2000; 342: 1866-1870.

17 Olschewski H, Ghofrani HA, Walmrath D, TemmesfeldWollbruck B, Grimminger F, Seeger W. Recovery from circulatory shock in severe primary pulmonary hypertension $(\mathrm{PPH})$ with aerosolization of iloprost. Intensive Care Med 1998; 24: 631-634. 
18 Olschewski H, Ghofrani HA, Walmrath D, et al. Inhaled prostacyclin and iloprost in severe pulmonary hypertension secondary to lung fibrosis. Am J Respir Crit Care Med 1999; 160: 600-607.

19 Dernaika TA, Beavin ML, Kinasewitz GT. Iloprost improves gas exchange in COPD patients with pulmonary arterial hypertension. Am J Respir Crit Care Med 2008; 177: A443.

20 Krowka MJ, Ahmad S, de Andrade JA, et al. A randomized, double-blind, placebo-controlled study to evaluate the safety and efficacy of iloprost inhalation in adults with abnormal pulmonary arterial pressure and exercise limitation associated with idiopathic pulmonary fibrosis. Chest 2007; 132: Suppl., 633S.

21 Olschewski H, Simonneau G, Galie N, et al. Inhaled iloprost for severe pulmonary hypertension. $N$ Engl J Med 2002; 347: 322-329.

22 McLaughlin VV, Oudiz RJ, Frost A, et al. Randomized study of adding inhaled iloprost to existing bosentan in pulmonary arterial hypertension. Am J Respir Crit Care Med 2006; 174: 1257-1263.

23 Hoeper MM, Leuchte H, Halank M, et al. Combining inhaled iloprost with bosentan in patients with idiopathic pulmonary arterial hypertension. Eur Respir J 2006; 28: 691-694.
24 Opitz CF, Wensel R, Winkler J, et al. Clinical efficacy and survival with first-line inhaled iloprost therapy in patients with idiopathic pulmonary arterial hypertension. Eur Heart J 2005; 26: 1895-1902.

25 D'Alonzo GE, Barst RJ, Ayres SM, et al. Survival in patients with primary pulmonary hypertension. Results from a national prospective registry. Ann Intern Med 1991; 115: 343-349.

26 Bayer Schering Pharma AG. Open-label, uncontrolled, longterm surveillance study of iloprost aerosol inhalation therapy in the treatment of patients with primary or secondary pulmonary hypertension. www.clinicalstudyresults.org/ drugdetails $/$ ?company_id $=73 \&$ indication_id $=854 \&$ sort $=$ c. company_name\&page $=1 \& d r u g \_i d=2423$ Date last updated: May 2007. Date last accessed: December 16, 2008.

27 Olschewski H, Nikkho S, Behr J, et al. Long-term survival in patients with pulmonary hypertension inhaling iloprost. Eur Heart J 2003; 24: 482 (abstract 2567).

28 Frost AE, the STEP investigators. STEP-open label extension: long-term benefits of inhaled iloprost (ILO) addition to bosentan for treatment of pulmonary arterial hypertension (PAH). Am J Respir Crit Care Med 2007; 175: Suppl., A1001. 